\title{
PRODUÇÃO DE MUDAS DE TOMATE CV. SANTA CRUZ EM DIFERENTES SUBSTRATOS
}

\section{SEEDLINGS OF TOMATO CV. SANTA CRUZ ON DIFFERENT SUBSTRATES}

Fernando Barnabé CERQUEIRA ${ }^{[1 ; *]}$, Gilson Araújo FREITAS ${ }^{[2]}$, Clayton de Jesus MACIEL ${ }^{[3]}$, Jefferson Santana da Silva CARNEIRO ${ }^{[2]}$ e Rubson da Costa LEITE ${ }^{[2]}$

${ }^{[1]}$ Universidade Federal do Amazonas (UFAM), Setor Sul, Bloco "M" Av. Gal. Rodrigo Otávio Jordão Ramos, no 3000. CEP: 69.077-00, Manaus-AM, Brasil. fernando1.981@hotmail.com

[2] Universidade Federal do Tocantins (UFT), Campus Gurupi. Rua Badejós, Chacarás 69/72, Lt 07, Zona rural. 77402-970. Gurupi-TO, Brasil. carneirojss@yahoo.com.br; rubsonif@gmail.com

${ }^{[3]}$ Faculdade de Guaraí (FAG), Avenida JK no 2541, Setor universitário, CEP: 77700-000. Guaraí-TO, Brasil. claytonjmaciel@gmail.com

*Autor para correspondência: araujoagro@hotmail.com

\begin{tabular}{|c|c|}
\hline INF. ARTIGO & RESUMO \\
\hline \multicolumn{2}{|r|}{0} \\
\hline Aceito: 17/04/2015 & \multirow{8}{*}{$\begin{array}{l}\text { O substrato utilizado na produção de mudas exerce papel primordial, no } \\
\text { desenvolvimento inicial da planta. Neste sentido, objetivou-se avaliar a produção de } \\
\text { mudas de tomate (Lycopersicum esculentum Mill.) em função de diferentes } \\
\text { substratos. O delineamento experimental foi o inteiramente casualizado, com cinco } \\
\text { tratamentos (T1 - Casca de arroz carbonizada (CAC); T2 - Orgânico; T3 - Casca de arroz } \\
\text { carbonizada + Húmus de minhoca na proporção 1:1; T4 - Húmus de minhoca e T5 - } \\
\text { Germinar) e quatro repetições. Analisou-se a altura de plantas, diâmetro de colmo, } \\
\text { comprimento de raiz, volume de raiz, massa seca da raiz, massa seca da parte aérea, } \\
\text { massa seca total, área foliar, índice de velocidade de germinação e índice de } \\
\text { qualidade de desenvolvimento. Observou - se que os resultados obtidos } \\
\text { demonstraram que o tipo de substrato interfere no desenvolvimento e qualidade da } \\
\text { muda de tomate. Dentre os substratos, o melhor desempenho das mudas foi } \\
\text { observado no substrato orgânico (T2), o qual, proporcionou melhor qualidade das } \\
\text { mudas em relação aos demais tratamentos. }\end{array}$} \\
\hline Publicado: 05/06/2015 & \\
\hline Document Object Identifier & \\
\hline 10.18067/jbfs.v2i2.21 & \\
\hline $\begin{array}{l}\text { Editor: V. H. G. Sales } \\
\text { jbfs@ifap.edu.br } \\
\text { ID JBFS0212014 }\end{array}$ & \\
\hline Avaliação às cegas por pares & \\
\hline Prot. $0212015 R 01$ & \\
\hline Prot. $0212015 R 02$ & \\
\hline
\end{tabular}

Copyright: (C) 2015

JBFS all rights (BY NC SA)

Palavras-chave: Lycopersicum esculentum, casca de arroz carbonizada, orgânico

ABSTRACT - The substrate used in the production of seedlings plays a key role in the initial development of the plant. In this sense, the objective was to evaluate the production of tomato seedlings (Lycopersicum esculentum Mill.) with different substrates. The experimental design was completely randomized, with five treatments (T1 - carbonized rice husk (CAC); T2 - Organic; T3 - carbonized rice husks + Earthworm casting in the ratio 1: 1; T4 - Earthworm casting; and T5 - germinate) and four replicates. Plant height, stem diameter, root length, root volume, root dry mass, shoot dry weight, total dry mass, leaf area, germination speed index, and developing quality index were analyzed. The type of substrate does affect the growth and quality of the tomato's changes. Among the substrates, the best seedling performance was observed in substrate (T2).

Keywords: Lycopersicum esculentum arbonized rice hull Organic

Financiamento: Os autores reportam que não houve auxílio ou suporte financeiro.

Conflito de interesse: Os autores declaram que não há conflito de interesse.

Como referenciar esse documento (ABNT):

CERQUEIRA, F. B.; FREITAS, G. A.; MACIEL, C. J.; CARNEIRO, J. S. S.; LEITE, R. C. Produção de mudas de tomate cv. Santa cruz em diferentes substratos. Journal of Bioenergy and Food Science, Macapá, v.2, n.2, p.39-45, abr./jun. 2015. DOI:10.18067/jbfs.v2i2.21

\section{INTRODUÇÃO}

O tomateiro (Lycopersicum esculentum Mill.) é uma das hortaliças mais difundidas no mundo, sendo cultivado nas mais diferentes latitudes geográficas em campo ou em cultivo protegido (PEREIRA, 2010). Sua aceitação deve-se principalmente por suas qualidades organolépticas e o seu valor como alimento funcional devido às propriedades antioxidantes do licopeno. Dentre as 
hortaliças cultivadas no Brasil, a cultura do tomateiro merece destaque por ocupar o segundo lugar em importância econômica (RONCHI et al., 2010).

Uma das principais etapas do sistema produtivo do tomate é a produção de mudas de qualidade, pois delas dependem o desempenho final das plantas no campo de produção. Segundo Oviedo (2007) o sucesso da produção do tomateiro depende da alta qualidade da muda, sendo um fator essencial, pois a condição inicial da planta influencia no pegamento das mudas, produção precoce, produção total e tamanho dos frutos. Essa produção é altamente dependente da utilização de insumos a qual o substrato tem se destacado em importância, devido à sua ampla utilização na produção de mudas.

Neste contexto, o substrato utilizado na produção de mudas pode ser formado de matériaprima de origem mineral, orgânica ou sintética, de um só material ou de diversos materiais em misturas, desde que apresentem características químicas, físicas e biológicas desejáveis (KANASHIRO, 1999). Além disso, características relacionadas como maior precocidade, redução de contaminação por fitopatógenos, maior aproveitamento de muda/semente e menos estresse no transplante faz com que este insumo proporcione maior rendimento em relação aos métodos tradicionais (SILVEIRA et al., 2002).

Um bom substrato é aquele que proporciona boas condições de umidade,teor de nutrientes, disponibilidade de nutrientes e de água, macro e microporosidade, capacidade de troca de cátions, boa agregação às raízes e uniformidade(ENSINAS et al.,2011; COSTA et al., 2013). Dificilmente há um substrato com todas essas características benéficas, necessitando de pesquisas com diferentes tipos de substratos para o conhecimento das características presentes e do potencial de cada um para a cultura do tomate.

Diante do exposto, o presente estudo teve como objetivo avaliar a produção de mudas de tomate (Lycopersicum esculentum Mill.) em função de diferentes substratos.

\section{MATERIAIS E MÉTODOS}

O experimento foi conduzido em casa de vegetação no período de agosto a setembro de 2012, na Fazenda Santo Antônio, localizada no município de Fortaleza do Tabocão, na região central do estado do Tocantins. A latitude é de $9^{\circ} 3^{\prime}$ $27^{\prime \prime}$ sul e longitude $48^{\circ} 31^{\prime} 9^{\prime \prime}$ oeste com altitude de $227 \mathrm{~m}$, apresentando clima tropical chuvoso (AW) com verão chuvoso e inverno seco, precipitação de inverno menor que $60 \mathrm{~mm}$ e temperatura média de 32ㅇ (KOPPEN, 1948).

A semeadura foi realizada no dia 02/08/2012, sendo utilizado bandejas de polietileno expandido (isopor) com volume de $12,39 \mathrm{~cm}^{3}$, sendo as dimensões de cada célula $6 \times 5 \mathrm{~cm}$, totalizando 200 células.

O delineamento experimental utilizado foi o inteiramente casualizado (DIC) com quatro repetições, sendo composto por cinco tratamentos (T1 - Casca de arroz carbonizada (CAC); T2 - orgânico; T3 - CAC + Húmus de minhoca na proporção de 1:1; T4 - Húmus de minhoca e T5 - Germinar). Os tratamentos foram alocados nas bandejas em fileiras de forma intercalada, dividindo os tratamentos com bordaduras de três fileiras sendo cada parcela útil constituída por oito plântulas. As composições químicas dos substratos estão representadas na Tabela 1.

Tabela 1. Caracterização química dos diferentes substratos utilizados na produção de mudas de tomate cv. Santa Cruz, na cidade de Fortaleza do Tabocão-TO, Brasil.

Table 1. Chemical characterization of the different substrates used in the production of tomato seedlings $\mathrm{cv}$. Santa Cruz, in city Fortaleza do Tabocão-TO, Brazil.

\begin{tabular}{|c|c|c|c|c|c|c|c|c|c|c|c|c|c|c|}
\hline \multirow[t]{2}{*}{ Substratos } & $\mathrm{N}$ & $\mathrm{P}$ & $\mathrm{K}$ & $\mathrm{Ca}$ & $\mathrm{Mg}$ & $S$ & $\mathrm{Cu}$ & $\mathrm{Fe}$ & $\mathrm{Mn}$ & $\mathrm{Zn}$ & Co & Mo & $\mathrm{B}$ & $\mathrm{MO}$ \\
\hline & \multicolumn{14}{|c|}{$\mathrm{g} / \mathrm{kg}$} \\
\hline Germinar & 5,8 & 2,5 & 1,7 & 6 & 1,1 & 4,6 & 2 & 6100 & 200 & 60 & 1,5 & 2 & 6,3 & 4,2 \\
\hline CAC & 6 & 2,5 & 4,2 & 11 & 2 & 4 & 10 & 6200 & 2300 & 60 & 1 & 2 & 7 & 4,8 \\
\hline Húmus & 7 & 1,9 & 2,1 & 6 & 2,5 & 3,5 & 6 & 9200 & 300 & 80 & 1,5 & 2,5 & 6 & 9 \\
\hline Orgânico & 7 & 1,9 & 1,3 & 5,8 & 1,4 & 1 & 3 & 22000 & 400 & 8 & 1,3 & 2,4 & 6,5 & 12 \\
\hline
\end{tabular}

A cultivar utilizada foi a Santa Cruz com germinação de $90 \%$ e pureza física $99,9 \%$, sendo colocado duas sementes por célula à $3 \mathrm{~mm}$ de profundidade. Aos 31 dias após a semeadura, foram avaliadas as seguintes características: altura de plantas (AP) realizada com o auxílio de um paquímetro digital, considerando a distância entre colo e o ápice do meristema apical; diâmetro de 
colmo (DC) realizado com o auxílio de um paquímetro digital para mensuração das plantas considerando um centímetro acima do colo da muda; volume de raiz (VR) determinado com auxílio de uma proveta graduada de $50 \mathrm{ml}$ contendo um volume conhecido de água, sendo a resposta obtida a partir da diferença direta do volume de raízes, pela equivalência de unidades (Basso, 1999); massa seca da raiz (MSR), massa seca da parte aérea (MSPA) e massa seca total (MST) foram determinadas a partir de uma planta submetida à secagem em estufa de circulação de ar forçado a 70 ㅇ C até peso constante; área foliar (AF); índice de velocidade de germinação (IVG) e índice qualidade de desenvolvimento (IQD).

$O$ índice de velocidade de germinação (IVG) foi determinado a partir da metodologia descrita por Maguime (1962) onde se procedeu ao registro diário do número de sementes germinadas até 6으 dia DAS, sendo considerando como emergidas, as plântulas que apresentaram cotilédones totalmente livres e normais.

A determinação da área foliar foi a partir de imagens digitais. Este método consiste na captura de imagens das folhas por meio de uma câmera fotográfica e seu processamento pelo software SPRING (Sistema de processamento de informações georeferenciadas) (CAMARA et al., 1996).

Para cálculo da área foliar considerou-se como base a escala (variável) e a resolução em que foram obtidas as imagens (300 dpi). Os dados obtidos foram usados no software SPRING, para determinar a área de cada pixelque compõe a imagem e integrar os elementos pertencentes à mesma categoria.

O processo de determinação da escala da fotografia no SPRING procedeu da seguinte forma: as folhas foram dispostas abertas sobre uma cartolina de coloração azul, com dimensões de $25 \mathrm{x}$ $25 \mathrm{~cm}$. Para eliminação das ondulações e rugosidades colocou-se uma chapa de vidro transparente com as mesmas dimensões da cartolina. Após, foi efetuado o cálculo da resolução inicial, sem correção, para os valores $X$ e $Y$ que foram feitas pela Equação 1:

res_ini $=2,54 / d p i$

Eq (1)

Sendo que resini é a resolução inicial do eixo i $(\mathrm{cm})$ e dpi, a resolução em que é obtida a imagem (dpi).

Após, procedeu com a importação das imagens pelo software SPRING e, devido ao ângulo e distância variáveis em que foram obtidas, fez se necessário a correção da escala na análise de cada foto, conforme a Equação 2: res_fin $=r e s \_i n i\left(\left(V o \_e i\right) /\left(V m_{-} e i\right)\right)$

Eq (2)

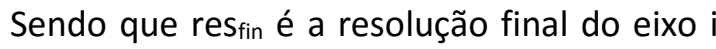

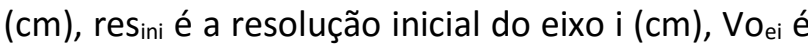
o valor original do eixo i e $\mathrm{Vm}_{\mathrm{ei}}$ é o valor medido do eixo i.

Em seguida foi determinado as dimensões dos pixelsem $X$ e $Y$ e as imagens foram classificadas automaticamente pelo software, o que permitiu dimensionar a área de cada folha, de acordo com a seguinte Equação 3:

$A F \_i d=\Sigma r e s \_f i n x i$ Xres_finyi $(i=1) \quad$ Eq (3)

Onde $\mathrm{AF}_{\mathrm{id}}$ é definido como $\mathrm{AF}$ medida pelo método imagem digital $\left(\mathrm{cm}^{2}\right)$,

i é o índice utilizado para representar os elementos classificados como folha,

res $_{\text {finxi }}$ é a resolução final do pixel, no eixo $X$, na posição i, e

res finyi é a resolução final do pixel, no eixo $Y$, na posição i.

Para o cálculo do índice de qualidade do desenvolvimento (IQD) foi utilizada a metodologia de Dickson et al. (1960) considerando-se os indicadores de altura, diâmetro do colo das mudas, massa seca da parte aérea, das raízes e de massa seca total, conforme a Equação 4:

$$
I Q D=P M S T \text { otal } /((A P / D C)+(P M S P A / P M S R)) \mathbf{E q}(4)
$$

Onde:

IQD = Índice de desenvolvimento de Dickson

MST = Massa seca total $(\mathrm{g})$

$\mathrm{H}=\operatorname{altura}(\mathrm{cm})$

$D C=$ diâmetro do colo $(\mathrm{cm})$

PMSPA = Peso da matéria seca da parte aérea $(\mathrm{g})$

PMSRA = Peso da matéria seca da raiz (g).

Os dados obtidos foram submetidos à análise de variância (ANAVA), utilizando o programa ASSISTAT versão 7.6 (Silva, 2008), e quando o valor de $F$ apresentou significativo ao nível de $5 \%$ de probabilidade, aplicou-se o teste de Tukey. Os gráficos dos parâmetros avaliados foram plotados utilizando o programa estatístico SigmaPlot versão 10.

\section{RESULTADOS}

A altura de plantas (AP) e diâmetro de colmo (DC) comportaram-se de maneira semelhantes entre os tratamentos (Tabela 2). O tratamento T2 (orgânico) foi superior aos demais tratamentos, apresentando um incremento de $43,3 \%$ em altura de plantas e $25,9 \%$ em diâmetro de colmo quando 
comparado com o tratamento de menor valor, $\mathrm{T} 1$ (casca de arroz carbonizada). Os tratamentos T3 (casca de arroz carbonizada + húmus), T4 (húmus) apresentaram o mesmo desempenho para as características citadas, atingindo valores semelhantes ao tratamento T5 (Germinar ${ }^{\circ}$ ) que é representado pelo substrato comercial. Ferreira et al. (2014) determinando o comportamento das mudas de tomate e couve em diferentes combinações de vermicompostos constituídos por esterco bovinos e esterco de pequenos ruminantes verificaram que a AP variou de 10,637 a $14,232 \mathrm{~cm}$ e DC variaram de 2,014 a 2,483 mm. Por outro lado, Rodrigues et al. (2010) ao avaliarem substratos a base de composto orgânico e solo verificaram médias inferiores às obtidas no presente trabalho correspondente a $4,234 \mathrm{~cm}$ para AP e $0,129 \mathrm{~mm}$ para o DC em mudas de tomate.

Tabela 2. Altura de plantas (AP), diâmetro de colmo (DC), comprimento de raiz (CR), volume de raiz (VR), massa seca da raiz (MSR), massa seca da parte aérea (MSPA) e massa seca total (MST) em mudas de tomate cultivadas em bandejas sob diferentes substratos, Fortaleza do Tabocão - TO.

Table 2. plant height $(A P)$, stem diameter $(D C)$, root length (CR), root volume (RV), dry root mass (MSR), dry weight of shoot (MSPA) and total dry matter (MST) on tomato seedlings grown in trays under different substrates, in city Fortaleza do Tabocão - TO, Brazil.

\begin{tabular}{ccccccc}
\hline Tratamentos & AP $(\mathrm{cm})$ & DC $(\mathrm{mm})$ & VR $\left(\mathrm{cm}^{3}\right)$ & MSR $(\mathrm{g})$ & MSPA $(\mathrm{g})$ & MST $(\mathrm{g})$ \\
\hline T1 & $6,01 \mathrm{c}$ & $1,40 \mathrm{c}$ & $0,10 \mathrm{~b}$ & $0,0077 \mathrm{~b}$ & $0,0116 \mathrm{e}$ & $0,019 \mathrm{c}$ \\
T2 & $10,6 \mathrm{a}$ & $1,89 \mathrm{a}$ & $0,18 \mathrm{a}$ & $0,0152 \mathrm{a}$ & $0,0471 \mathrm{a}$ & $0,063 \mathrm{a}$ \\
T3 & $8,07 \mathrm{~b}$ & $1,63 \mathrm{~b}$ & $0,10 \mathrm{~b}$ & $0,0090 \mathrm{~b}$ & $0,0258 \mathrm{~d}$ & $0,035 \mathrm{~b}$ \\
T4 & $8,20 \mathrm{~b}$ & $1,65 \mathrm{~b}$ & $0,16 \mathrm{a}$ & $0,0130 \mathrm{a}$ & $0,0298 \mathrm{c}$ & $0,042 \mathrm{~b}$ \\
T5 & $8,32 \mathrm{~b}$ & $1,64 \mathrm{~b}$ & $0,16 \mathrm{a}$ & $0,0155 \mathrm{a}$ & $0,0348 \mathrm{~b}$ & $0,050 \mathrm{ab}$ \\
\hline QM & $21,4^{* *}$ & $0,24^{* *}$ & $0,0057^{* *}$ & $0,00005^{* *}$ & $0,0067^{* *}$ & $0,0010^{* *}$ \\
\hline C.V. (\%) & 3,71 & 1,94 & 16,35 & 14,23 & 15,12 & 17,38 \\
\hline
\end{tabular}

Médias com mesma letra na coluna não diferem entre si pelo teste de Tukey a 5\% de probabilidade. T1(Casca de arroz carbonizada), T2 (Orgânico), T3(Casca de arroz carbonizada + Húmus de minhoca), T4(Húmus de minhoca), T5(Germinar). ** significativo a $5 \%(\mathrm{P}=0,05)$.

Averages with a the same letter in the column do not differ by Tukey test at 5\% probability. T1 (carbonized rice husk); T2 (Organic); T3 (carbonized rice husk + Humus earthworm); T4 (Humus earthworm) and T5 (Sprouting). ** Significant at 5\% $(P=0.05)$.

Quanto ao volume de raiz (VR) pode-se observar que os tratamentos T2, T4 e T5 não apresentaram diferenças estatísticas $(p=0,05)$, (Tabela 2). Porém, se diferiram $(p=0,05)$ dos tratamentos T1 e T3 apresentando maiores valores. O mesmo comportamento foi observado na característica massa seca da raiz (MSR). 0 comportamento observado no VR e na MSR pode estar associado à capacidade de retenção de água desses substratos, que propiciaram acúmulo de massa seca pelas plantas e maior lignificação dos tecidos (PEREIRA et al., 2012).

A massa seca da parte aérea (MSPA) teve seu peso afetado nos diferentes substratos avaliados, sendo constatadas diferenças estatísticas $(p=0,05)$ entre todos os tratamentos (Tabela 2). A maior média de MSPA encontrada foi obtida com o tratamento T2 $(0,0471 \mathrm{~g})$, por outro lado o tratamento $\mathrm{T} 1$, a base de casca de arroz carbonizada, apresentou a menor média $(0,0116 \mathrm{~g})$. Isso significa um aumento de $75 \%$ de MSPA nas mudas produzidas sob substrato orgânico. $O$ mesmo ocorreu para massa seca total (MST) onde o T2 apresentou um aumento de $69,84 \%$ em relação ao T1. Steffen et al. (2010) determinando o desempenho de diversos substratos vermicompostados constituídos por esterco curtido de bovinos, casca de arroz natural e carbonizada na produção de mudas de tomate verificaram valores máximos de 0,035 e mínimos de 0,010 em gplanta $^{-1}$ de MST, corroborando com os resultados encontrados no presente trabalho.

Essas diferenças entre os tratamentos observadas em todas as características avaliadas podem estar relacionadas com as características físicas, químicas e biológicas dos substratos. Segundo Menezes (1997), dentre os fatores que interferem nas características das mudas está à fertilidade do substrato, que envolve componentes como nutrientes, água, aeração, reação do solo, microrganismos, textura e temperatura, e estes, num estádio ótimo, conferem a fertilidade desejável. Freitas et al. (2013) relatam que devido ao limitado volume no crescimento das raízes, os substratos devem ser capazes de proporcionar fornecimento constante de água, oxigênio e nutrientes às plantas garantido assim ambientes estáveis ao desenvolvimento das plantas.

Quanto a Área foliar a cultivar de tomate Santa cruz apresentou resultados distintos em 
função dos diferentes substratos utilizados (Figura 1). O tratamento $T 2$ formado pelo substrato orgânico foi o que apresentou o maior valor $(0,0055$ $\mathrm{cm}^{2}$ ), isso corresponde a um aumento de $75,64 \%$, $27,27 \%, 40 \%, 14,54 \%$ em relação aos tratamentos $\mathrm{T} 1, \mathrm{~T} 3, \mathrm{~T} 4$ e T5, respectivamente. Os resultados observados para a característica área foliar apresentaram o mesmo comportamento da característica massa seca da parte aérea (Tabela 1), possivelmente há uma relação direta entre as características, pois o aumento de um reflete no aumento do outro.

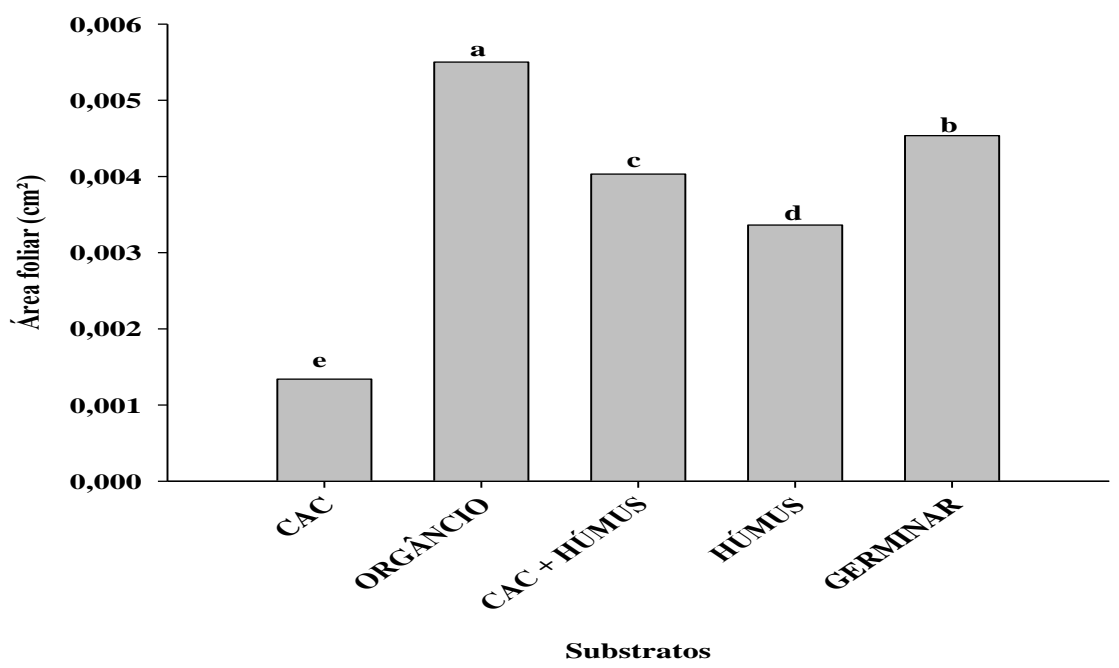

Figura 1. Área foliar de mudas de tomate cv. Santa Cruz em função dos diferentes substratos, Fortaleza do Tabocão-TO. Médias com mesma letra minúscula nos substratos, não diferem entre si pelo teste de Tukey a $5 \%$ de probabilidade.

Figure 1. Leaf area cv tomato seedlings. Santa Cruz depending on the different substrates, Tabocão-TO Fortress. Averages with a same letter on substrates, do not differ by Tukey test at $5 \%$ probability.

Para o índice de velocidade de germinação foi observado diferenças entre os tratamentos estudados (Figura 2). O tratamento T2 formado pelo substrato orgânico apresentou resultados superiores em relação à T3, T4 e T5, diferindo-se estatisticamente desses tratamentos. Um aspecto observado no presente trabalho foi que o tratamento T5 representado pelo substrato comercial Germinar apresentou o menor valor de índice de velocidade de germinação dentre todos os tratamentos. Esse fato aumenta o tempo de formação e produção de mudas de tomate, aumentando os custos de produção e diminuindo a eficiência do sistema.

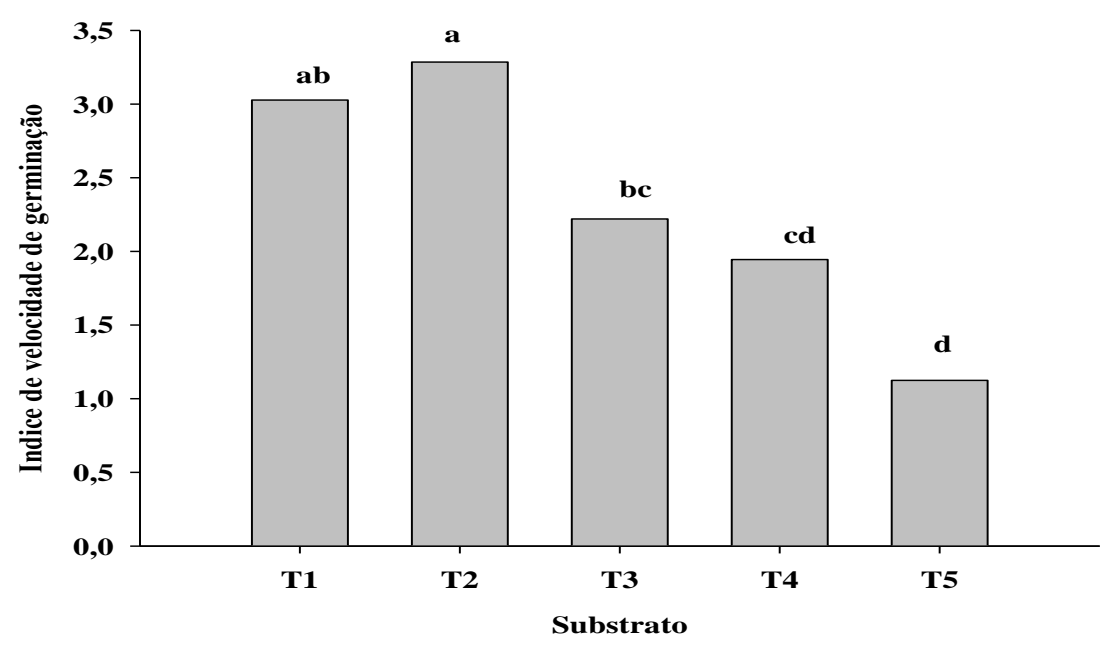

Figura 2. Índice de velocidade de germinação (IVG) de mudas de tomate cv. Santa Cruz em função dos diferentes substratos, Fortaleza do Tabocão-TO. Médias com mesma letra minúscula nos substratos, não diferem entre si pelo teste de Tukey a $5 \%$ de probabilidade.

Figure 2. Germination speed index (IVG) cv tomato seedlings. Santa Cruz depending on the different substrates, Tabocão-TO Fortress. Averages with a same letter on substrates, do not differ by Tukey test at 5\% probability.

O índice de qualidade de Dickson desenvolvimento (IQD) para as mudas de tomateiro apresentou resultados distintos em função dos diferentes substratos utilizados. Os valores de IQD 
variaram de 0,0037 a 0,0073 . O tratamento $\mathrm{T} 2$ apresentou o melhor IQD para mudas de tomateiro e os tratamentos T1 e T3 apresentaram os piores, quando comparados com os demais tratamentos

(Figura 3).

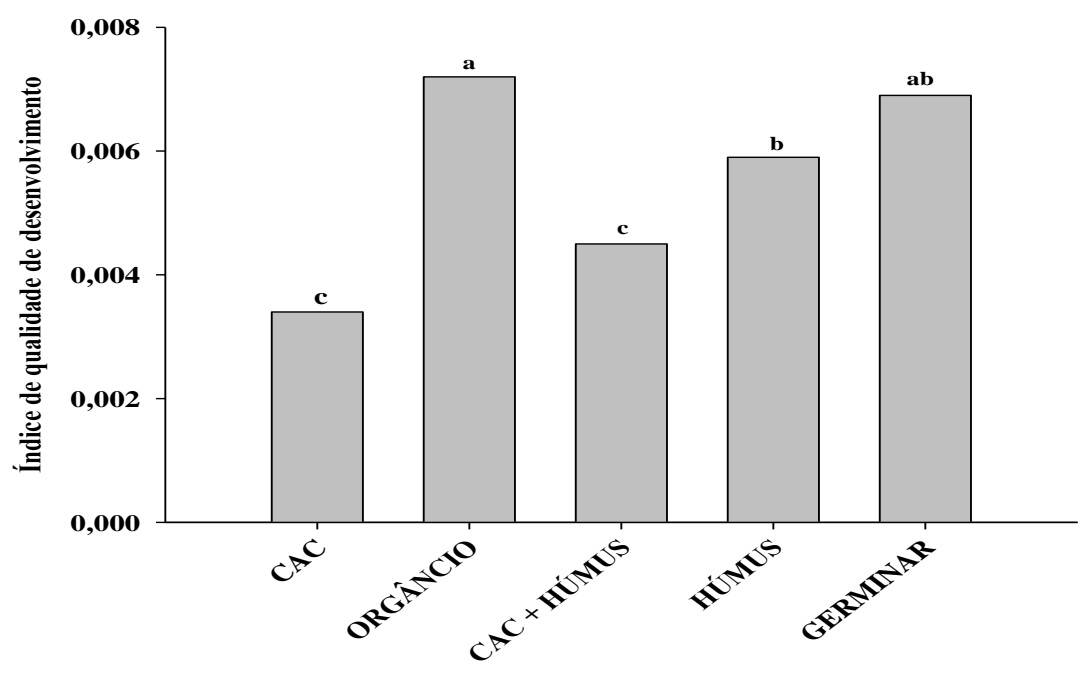

Substratos

Figura 3. Índice de qualidade de desenvolvimento (IQD) de mudas de tomate cv. Santa Cruz em função dos diferentes substratos, Fortaleza do Tabocão-TO. Médias com mesma letra minúscula nos substratos, não diferem entre si pelo teste de Tukey a $5 \%$ de probabilidade.

Figure 3. Development Quality Index (IQD) cv tomato seedlings. Santa Cruz in function on the different substrates, in city FortalezaTabocão-TO, Brazil. Averages with a same letter on substrates, do not differ by Tukey test at $5 \%$ probability.

O índice de qualidade de Dickson é um bom indicador da qualidade das mudas pois é considerado o vigor e o equilíbrio da distribuição da biomassa na muda (AZEVEDO et al., 2010). No entanto, não foi observado na literatura resultados de IQD para produção de mudas de tomateiro. Em mudas de alface, Freitas et al. (2013), estudando diferentes substratos alternativos, observaram que os valores de qualidade das mudas variaram entre 0,0001 e 0,00079 . Outros estudos foram realizados com espécies florestais, estabelecendo como padrão de IQD o valor mínimo de 0,20 (HUNT, 1990). A maior qualidade de muda de tomateiro apresentada pelo substrato orgânico e as menores apresentada pelos substratos casca de arroz carbonizada e casca de arroz carbonizada + húmus, pode estar relacionado com a oferta de nutrientes disponíveis que cada substrato possui, provavelmente o substrato orgânico disponibilizou maiores quantidades de nutrientes para o sistema radicular das plantas, promovendo aumento.

\section{CONCLUSÕES}

Os diferentes substratos proporcionaram efeito positivo na produção de mudas de tomate. $\mathrm{O}$ melhor desempenho das mudas foi observado no substrato orgânico (T2), o qual, proporcionou melhor qualidade das mudas em relação aos outros tratamentos. Por outro lado, o substrato com casca de arroz carbonizada (T1), não proporciona condições favoráveis para o desenvolvimento de mudas, inviabilizando sua utilização como substrato na forma pura.

\section{REFERÊNCIAS}

AZEVEDO, I. M. G. DE; ALENCAR, R. M. DE; BARBOSA, A. P.; ALMEIDA, N. O. DE. Estudo do crescimento e qualidade de mudas de marupá (Simarouba amara Aubl.) em viveiro. Acta Amazônica, v. 40, p. 157-164, 2010.

BASSO, SIMONE. M. S. Caracterização morfológica e fixação biológica de nitrogênio de espécies de Adesmia DC e Lotus L. 1999. 268f. Tese (Doutorado). Universidade Federal do Rio Grande do Sul, Porto Alegre-RS.
CAMARA, G.; et al. Spring: integrating remote sensing and GIS byobject-oriented data modeling. In: Computers \& Graphics: Dordrecht, v. 20, n. 3, p. 395-403, 1996.

COSTA, L. A. M.; COSTA, M. S. S. M.; PEREIRA, D. C.; BERNARDI, F. H.; SÍLVIA M. Avaliação de substratos para a produção de mudas de tomate e pepino. Revista Ceres, v. 60, p. $675-682,2013$.

COSTA, L. M.; ANDRADE, J. W. de S.; ROCHA, A. C. da; SOUZA, L. de P.; FLÁVIO NETO, J. Avaliação de diferentes 
substratos para o cultivo de pepino (Cucumis sativus L.). Global Science Technology, v. 2, p. 21-26, 2009.

DICKSON, A.; LEAF, A. L.; HOSNER, J. F. Quality appraisal of white spruce and white pine seedling stock in nurseries. Forest Chronicle., v. 36: p.10-13, 1960.

ENSINAS, S.C.; MAEKAWA JUNIOR, M.T.; ENSINAS, B.C. Desenvolvimento de mudas de rúcula em diferentes combinações de substrato. Revista Científica Eletrônica de Agronomia, v. 18, p. 1-7, 2011.

FERREIRA, L. L.; ALMEIDA, A. E. S.; COSTA, L. R.; MEDEIROS, J. F. M.; PORTO, V. C. N. Vermicompostos como substrato na produção de mudas de tomate (Lycopersicon esculentum) e couve-folha (Brassica oleracea var. acephala). Revista Verde, v. 9, p. 256-263, 2014.

FREITAS, G. A.; SILVA, R. R.; BARROS, H. B.; MELO, A. V.; ABRAHÃO, W. A. P. Produção de mudas de alface em função de diferentes combinações de substratos. Revista Ciência Agronômica, v. 44, p. 159-166, 2013.

HUNT, G.E. Waste reduction Techniques and Technologies. New York: Mc-Graw Hill, p. 25-54, 1990.

KANASHIRO, S. Efeito de diferentes substratos na produção da espécie Aechemea fasciata (Lindley) Baker em vasos. 1999. 79p. Dissertação (Mestrado em Agronomia) Escola Superior de Agricultura Luiz de Queiroz, Piracicaba - SP.

KÖPPEN, W. Climatologia: com um estúdio de los climas de la tierra. New Gersey: Laboratory of Climatology, 1948. 104 p.

LIMA, C. J. G. S.; OLIVEIRA, F. A.; MEDEIROS, J. F.; OLIVEIRA, M. K. T.; GALVAO, D. C.; Avaliação de diferentes bandejas e substratos orgânicos na produção de mudas de tomate cereja. Ciência Agronômica, v.40, p. 123-128, 2009.

MEDEIROS, D. C.; AZEVEDO, C. M. S. B.; MARQUES, L. F.; SOUSA, R. A.; OLIVEIRA, C. J. Qualidade de mudas de tomate em função do substrato e irrigação com efluente de piscicultura. Revista Brasileira de Agroecologia, v. 8, p. 170-175, 2013.

MENEZES, A. C. S. G. Efeito da matéria orgânica e do superfosfato simples no crescimento e nutrição de mudas de bananeira (Musa sp) cv. "Grand Naine", produzidas por cultura de tecidos. 1997. 63p. Dissertação (Mestrado). UFLA, Lavras-MG.

OVIEDO, V. R. S. Produção de tomate em função da idade da muda e volume dorecipiente. 2007.80p. Tese Doutorado. Escola Superior de agricultura Luiz de Queiroz, Piracicaba - SP.

PEREIRA D. C.; GRUTZMACHER P.; BERNARDI F. H.; MALLMANN L. S.; COSTA L. A. M.; COSTA M. S. S. M. Produção de mudas de almeirão e cultivo no campo, em sistema agroecológico. Revista Brasileira de Engenharia Agrícola e Ambiental, v.16, p. 1100-1106, 2012.

PEREIRA, M. A. B. Resposta agronômica e em póscolheita de genótipos de tomate em duas épocas de cultivo em Gurupi, Estado do Tocantins. 2010, 72p. Dissertação Mestrado, UFT, Gurupi-TO.

RODRIGUES, E.T.; LEAL, P.A.M.; COSTA, E.; PAULA, T.S.; GOMES, V.A. Produção de mudas de tomateiro em diferentes substratos e recipientes em ambiente protegido. Horticultura Brasileira, v. 28, p. 483-488, 2010.

RONCHI, C. P.; SERRANO, L. A. L.; SILVA. A. A.; GUIMARÃES, O. R. Manejo de plantas daninhas na cultura do tomateiro. Planta Daninha, v. 8, p. 215-228, 2010.

SILVA, F.A.S. (2008) - Sistema de Assistência Estatística ASSISTAT versão 7.6 beta (em linha). Departamento de Engenharia Agrícola [DEAG], CTRN, Universidade Federal de Campina Grande [UFCG], Paraíba, Brasil, Campina Grande. Versão Eletrônica, Disponível em: <http://www.assistat.com>, Acesso em: 18 Ago 2013.

SILVA, R. R.; RODRIGUES, L. U.; FREITAS, G. A.; MELO, A. V.; NASCIMENTO, I. R.; D'ANDRÉA, A. F. Influência de casca de arroz carbonizada em diferentes substratos na qualidade de mudas de tomateiro. Revista Brasileira de Ciências Agrária, v. 7, p. 803-809, 2012.

SILVEIRA, E. B. et al. Pó de coco como substrato para produção de mudas de tomateiro. Horticultura Brasileira, v. 20, n. 2, p. 211-216, 2002.

STEFFEN, G.P.K.; ANTONIOLLI, Z.I.; STEFFEN, R.B.; MACHADO, R.G. Casca de arroz e esterco bovino como substratos para a multiplicação de minhocas e produção de mudas de tomate e alface. Acta Zoológica Mexicana, v. 2, p. 333-34, 2010. 